\title{
Patient Education on Prostate Cancer Screening and Involvement in Decision Making
}

\author{
Alex H. Krist, $M D, M P H^{1}$ \\ Steven H. Woolf, MD, MPH \\ Robert E. Jobnson, $P b D^{3}$ \\ J. William Kerns, $M D^{4}$ \\ 'Department of Family Medicine, Fairfax \\ Family Practice Residency, Virginia \\ Commonwealth University, Fairfax, Va \\ ${ }^{2}$ Departments of Family Medicine, Epide- \\ miology, and Community Health, Virginia \\ Commonwealth University, Fairfax, Va \\ ${ }^{3}$ Departments of Family Medicine and \\ Biostatistics, Virginia Commonwealth \\ University, Fairfax, Va \\ ${ }^{4}$ Department of Family Medicine, \\ Shenandoah Valley Family Practice \\ Residency Program, Virginia Common- \\ wealth University, Fairfax, Va
}

\begin{abstract}
PURPOSE Many clinicians lack resources to engage patients in shared decision making for prostate cancer screening. We sought to evaluate whether previsit educational decision aids facilitate shared decision making.

METHODS This randomized controlled study compared a Web-based and a paper-based decision aid with no previsit education. Men aged 50 to 70 years undergoing a health maintenance examination at a large family practice were enrolled. The primary outcome was patient-reported level of control over the decision to be screened. Secondary outcomes included frequency of screening, patient knowledge, decisional conflict, and time spent discussing screening.
\end{abstract}

RESULTS A total of 497 men participated (75 control, 196 brochure, 226 Web site). Patients exposed to either aid were no more likely than control patients to report a collaborative decision: $36 \%$ of patients in each group reported equally sharing decision responsibility. Exposure to either decision aid increased patients' involvement in decision making compared with the control condition (Web site, $P=.03$; brochure, $P=.03$ ). Only $46 \%$ of control patients reported an active decision-making role, compared with $56 \%$ of Web site and $54 \%$ of brochure patients. Patients exposed to a decision aid answered a greater percentage of knowledge questions correctly $(54 \%$ control vs $69 \%$ Web site, $P<.001$, and vs $69 \%$ brochure, $P<.001)$ and were less likely to be screened $(94 \%$ control vs $86 \%$ Web site, $P=.06$, and vs $85 \%$ brochure, $P=.04$ ).

CONCLUSIONS Patients in the decision aid groups were more informed and more engaged in the screening decision than their control counterparts. Exposure did not promote shared decision-making control, however. Whether shared decision making is the ideal model and how to measure its occurrence are subjects for further research.

Ann Fam Med 2007;5:112-119. DOI: 10.1370/afm.623.

\section{INTRODUCTION}

$\mathrm{P}$ rostate cancer screening presents patients with an uncertain balance of benefits and harms because of gaps in supporting evidence. Recent research findings have added to rather than clarified the

Conflicts of interest: Dr Krist is a faculty member, practicing physician, and partial owner of Fairfax Family Practice Residency, where the study was conducted.

\section{CORRESPONDING AUTHOR}

Alex Krist, MD, MPH

Department of Family Medicine

Virginia Commonwealth University

3825 Charles Stewart Dr

Fairfax, VA 22033

ahkrist@vcu.edu controversy of whether to universally screen appropriate men. ${ }^{1,2}$ Since 1996, national screening recommendations have been consistent in recommending that clinicians not perform prostate cancer screening without first counseling patients about potential harms, benefits, and scientific uncertainties. ${ }^{3-5}$ One means to do this is through informed or shared decision making, an approach supported by the US Preventive Services Task Force (USPSTF). ${ }^{6}$ Shared decision making can help to incorporate the patient's values into the screening decision. ${ }^{7}$

According to the USPSTF, a decision is shared when the patient (1) understands the risk of the disease to be prevented ${ }_{i}(2)$ understands the preventive service, including risk, benefit, alternatives, and uncertainties; 
(3) weighs his values regarding the decision; and (4) is engaged in the decision at the desired level. ${ }^{6}$ Most clinicians are ill equipped to handle such a complicated decision-making process. Barriers include limited time and reimbursement for long discussions, ${ }^{8}$ medicolegal risks associated with deferred screening, ${ }^{9}$ patient expectations to be screened, ${ }^{10}$ and patient and physician biases and misconceptions about effectiveness. ${ }^{11}$

Decision aids are one potential strategy to promote shared decision making. Several paper-based and video aids have been developed for prostate cancer screening. ${ }^{12-16}$ These aids increase patient knowledge about prostate cancer screening and, in some studies, ${ }^{13,14}$ decrease patient interest in prostate-specific antigen (PSA) testing. Whether the aids promote shared decision making is unclear, however.

An additional practical challenge with video- or paper-based decision aids is getting the material to the patient for review before the clinical encounter at which the screening decision will be made. The Internet could provide an easy, automated, and cost-effective means for clinicians to deliver this information in advance. ${ }^{17,18}$ Many national organizations (eg, American Academy of Family Physicians, American Cancer Society, Centers for Disease Control and Prevention) have created Internet-based educational aids on prostate cancer. ${ }^{19-21}$ Only 1 aid has been formally studied, however, and it had relatively low use by participants and was less effective than a videotape aid. ${ }^{22}$

We hypothesized that review of a decision aid before a health maintenance examination would increase the rate with which patients and physicians shared control over decisions about prostate cancer screening. We also hypothesized that an online decision aid would be more effective than a mailed brochure because of its ease of distribution.

\section{METHODS}

We undertook a randomized controlled study comparing paper-based and Web-based decision aids vs no previsit education as a control. The methods detailed below have been described previously. ${ }^{23}$

\section{Setting}

The study was conducted at a single, large family practice center in suburban northern Virginia. The center hosts a community-based family practice residency program. The practice had 13 faculty, 8 second-year residents, and 8 third-year residents. A large proportion of patients were well-educated, Internet savvy, and affluent. ${ }^{24}$ Between June 2002 and June 2004, 2 weeks before their office visit, male patients aged 50 to 70 years who scheduled a health main- tenance examination were contacted by telephone. Patients were excluded if they had a history of prostate cancer, lacked Internet access, planned on having blood work before their visit, were enrolled in another prostate cancer investigation, or had already been enrolled in this study.

\section{Study Groups}

Patients were invited to view a Web-based decision aid, a mailed paper version of the decision aid, or no previsit educational material. The Web-based decision aid (http://www.acorn.fap.vcu.edu/psa), ${ }^{25}$ developed by the authors, presented information about prostate cancer, screening concepts, potential screening benefits, and known risks, as well as current uncertainties. The Web site was reviewed by a general decision aid expert and several content experts who had previously developed prostate cancer screening decision aids. The print brochure duplicated the content of the Web site. Control patients received usual care, in which they were not offered any previsit educational material and were not given any decision aids during discussions with physicians.

We stratified patient allocation by physician to ensure that each physician's patients were similarly distributed across the 3 study arms. Patients within strata were assigned randomly to receive no previsit education, the Web-based aid, or the brochure in a 1:3:3 ratio, respectively. At the time of enrollment, the allocation was concealed from the coordinator. After determining that the patient met inclusion criteria, reaching agreement on participation, and completing the consent process, the coordinator referred to pregenerated randomization tables to inform the participant to which arm he was randomized and to determine if it was necessary to send a decision aid. Although allocation was concealed, we made no attempts to blind physicians to the patient's group. Patients randomized to the Webbased aid were sent by e-mail a link to the Web site and were instructed to view the material before their visit. Patients randomized to the brochure aid were mailed the information with similar instructions to review the material before their visit.

\section{Outcomes}

We collected outcome data in a previsit structured telephone interview during enrollment and in selfadministered patient and physician exit questionnaires, both of which were completed immediately after the office visit in formats that enabled comparisons of patient and clinician responses to the same questions. The primary outcome was the patient-reported Control Preferences Scale (CPS) score, a measure previously used to evaluate patients' role in decision-making 
processes. ${ }^{26,27}$ We used the version with a single question to measure the CPS score, which assessed the respondent's perception of the locus of control over the prostate cancer screening decision. ${ }^{27}$ Response options ranged from $\mathrm{A}$ to $\mathrm{E}$ : A represented complete patient control without consideration of physician input, E represented complete physician control without consideration of patient input, and $\mathrm{C}$ represented a purely collaborative decision.

The patient questionnaire also assessed the patient's desired level of decision-making control to contrast perceptions of preferred vs actual control. Other outcomes measured by the patient questionnaire included prostate cancer screening knowledge, ${ }^{28}$ time spent discussing screening, topics covered in the discussion, Decisional Conflict Scale (DCS) score (which measures patients' level of conflict in making medical decisions), ${ }^{29}$ and whether a PSA test was ordered. The physician survey completed after each patient encounter assessed the same measures as the patient questionnaire except that knowledge and decisional conflict questions were not included.

\section{Analysis}

We used the CPS as a surrogate to measure shared decision making because no accepted measure existed when the study was designed. ${ }^{30}$ For the 3 study groups, we calculated the percentage of correct answers on the prostate cancer screening knowledge questions and the DCS score using previously published methodologies. ${ }^{29}$ We compared patient and physician responses for several measures (time spent discussing screening, whether a PSA test was ordered, and the number of screening topics addressed). Comparisons between groups were made on an intention-to-treat basis.

We performed statistical analyses using SAS version 9.1.3 (SAS Institute, Cary, NC). ${ }^{31}$ We used 2-sided tests with a significance level of .05 unless otherwise noted. We used a Wilcoxon rank sum test to evaluate for an increase in CPS choice C and a 1-sided Wilcoxon rank sum test to compare other CPS differences. (We elected to power for a 1-sided test when designing the study because a body of evidence shows that decision aids increase patient involvement. ${ }^{12,32,33}$ ) We used 2-sample $t$ tests to assess changes in DCS score, knowledge, time spent discussing screening, and number of topics discussed, and a Fisher exact test to assess differences in PSA test use and to assess the concordance between locus of actual decision-making control and that preferred by the patient. We used a binomial test with a nominal probability of 0.50 to assess if patients were more likely to report greater patient or greater physician control, the McNemar test to compare patient and physician reports on whether a PSA test was ordered, and a paired $t$ test to evaluate differences between patient and physician responses for time spent discussing screening and the number of topics discussed. This study was reviewed and approved by the Virginia Commonwealth University Institutional Review Board.

\section{RESULTS}

Of 1,073 men scheduled for health maintenance examinations, 497 (46\%) agreed to participate and were randomized to the control $(\mathrm{n}=75)$, brochure $(\mathrm{n}=$ $196)$, or Web site $(n=226)$ groups (Figure 1$)$. Of the 576 eligible patients who did not participate, most (n = 398) were excluded because we could not contact them before their office visits. The remaining 178 were excluded for 1 or more of the following reasons: 79 planned to have blood work before the examination, 33 declined participation, 30 had a history of prostate cancer, 29 had been previously enrolled, and 24 did not have Internet access. Questionnaires were completed by $87 \%$ of patients and $91 \%$ of physicians overall. A similar proportion of patients in each of the intervention groups reported reviewing the decision aid before their visit (Web site, 85\%; brochure, 88\%). Baseline demographics for the control, brochure, and Web site groups were similar (Table 1).

\section{Locus of Decision-Making Control}

A total of 431 participants answered the CPS questions. In the control, brochure, and Web site groups, 36\% of patients reported a purely collaborative decision (CPS choice C) (Figure 2). Exposure to either decision aid increased the patient's involvement in the decisionmaking process compared with the control condition (Web site, $P=.03$; brochure, $P=.03$ ) (Figure 2). This shift toward more patient control reflected in part the tendency of participants in the brochure and Web site groups to report having made the decision themselves - an active decision-making role (A or B locus of control) ( $46 \%$ of control patients vs $56 \%$ of Web site and $54 \%$ of brochure patients). Additionally, more patients in the control group reported that the physician made the decision-a passive decision-making role (D or E locus of control) (18\% of control patients vs $8 \%$ of Web site and $10 \%$ of brochure patients).

The decision aids did not increase concordance between locus of actual and preferred level of decisionmaking control reported by the patient $(P=.41)$ (Figure 3). Overall, $69 \%$ of respondents reported an actual locus that was consistent with their desired locus of decision-making control. Consistent with findings from a preliminary data analysis, ${ }^{23}$ more patients reported greater control than desired as opposed to the converse $(19 \%$ vs $11 \%, P=.003)$. 


\section{Figure 1. Flowchart of study patients.}

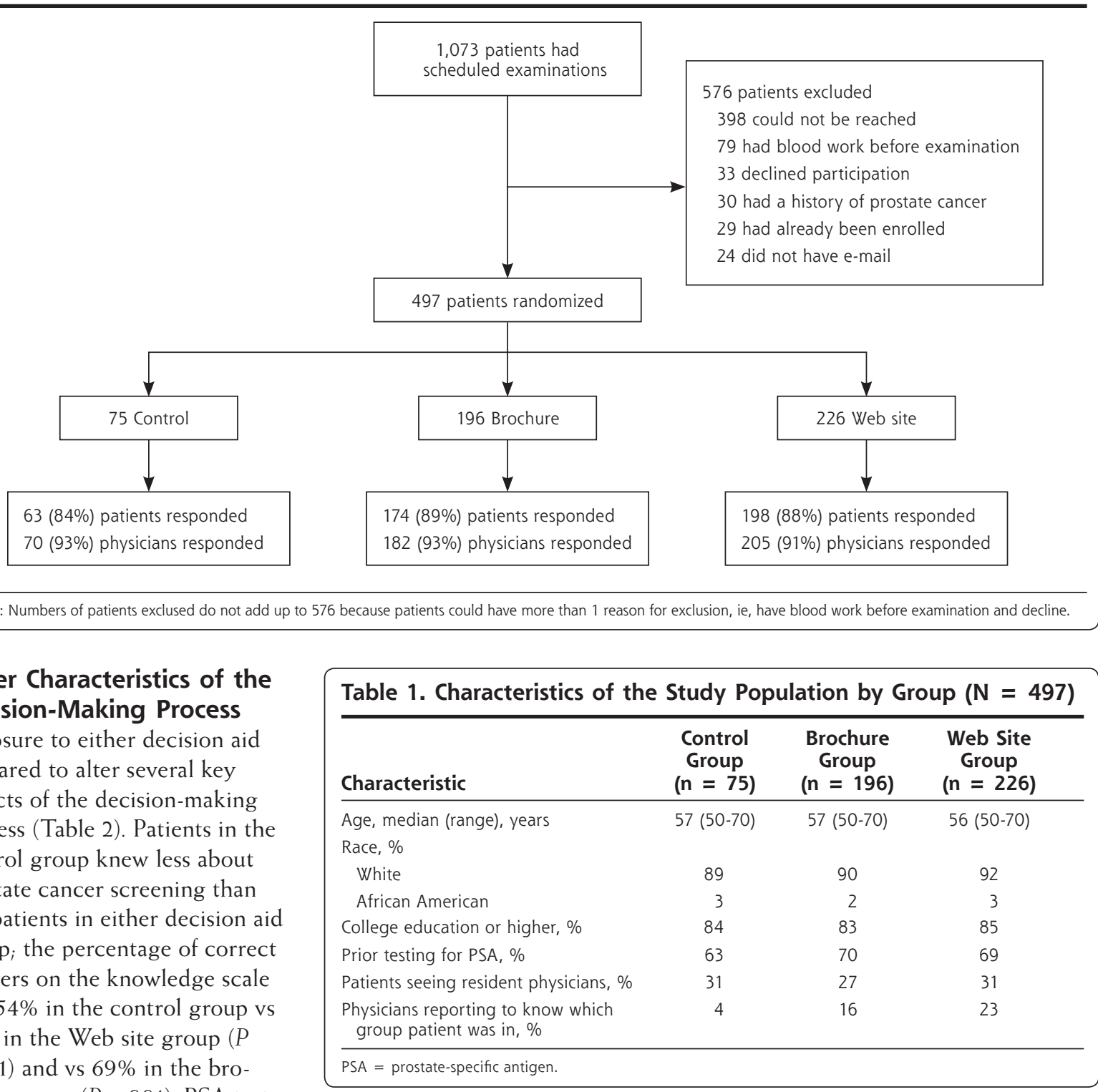

chure group $(P<.001)$. PSA test-

ing, as reported by the physician,

was $8 \%$ to $9 \%$ more common among control patients than among the decision aid groups (Table 2). In the control group, $85 \%$ of patients reported getting a PSA test, while $94 \%$ of physicians reported ordering the test $(P=.06)$. This finding suggests that as many as $9 \%$ of these patients receiving usual care may have received a PSA test without their knowledge. This discrepancy was not observed in either decision aid group.

The decision aids did not appear to alter the amount of time spent discussing prostate cancer screening or the number of prostate cancer screening topics that patients or physicians recalled addressing (Table 2). DCS scores among all 3 groups were equally low and did not differ significantly (control, 1.58; brochure,
1.54 ; and Web site, 1.55). Scores less than 2 reflect low decisional conflict and a relatively high likelihood of reaching a medical decision. ${ }^{29}$ At enrollment, $74 \%$ of men reported that they wanted a PSA test and $22 \%$ said that they were unsure. Patients' strong predisposition toward knowing whether they wanted a PSA test likely contributed to the low DCS scores.

\section{Physician Perceptions of the Decision- Making Process}

Combining the 3 groups, in only $34 \%$ of encounters did physicians and patients agree on the locus of decision-making control. Physicians tended to report that they had greater control over the decision than did 
patients, as measured by the CPS. Physicians thought that they spent less time discussing prostate cancer screening than did patients (3.8 vs 5.2 minutes, $P<.001)$ and, although not statistically significant, they reported discussing more topics (5.1 vs $4.9, P=.23)$. These patient-physician differences did not differ significantly across the control, brochure, and Web groups.

\section{DISCUSSION}

As proposed by the USPSTF, shared decision making represents a patient-clinician process in which both parties share information, jointly participate in decision making, and agree on a course of action. ${ }^{6}$ Guideline panels have advocated a pretest discussion of potential benefits and harms as part of the prostate cancer screening decision. ${ }^{3-5}$ The need for shared decision making has emerged in response to both information uncertainty and value uncertainty. Despite a wealth of research on prostate cancer screening, the magnitude of benefit, if any, is unknown. Even if a clear benefit to screening were to be found, value uncertainty would persist - a trade-off of risk vs benefit, the magnitude of each inherently dependent on individual patient values. Shared decision making has been viewed as an ethical duty to address both areas of uncertainty as well as to foster the patient-clinician partnership, promote patient autonomy, improve patient knowledge, and create more realistic patient expectations. ${ }^{6}$

Whether shared decision making is truly the right way for clinicians to approach the prostate cancer screening decision remains unclear. No evidence exists that such a process results in improved health outcomes. Additionally, shared decision making encounters a multitude of clinician and patient barriers. ${ }^{11}$ Finally, even if shared decision making were beneficial and feasible to deliver, some investigators have noted the paternalism of insisting that all clinicians use this approach. ${ }^{34}$

Figure 2. Locus of decision-making control $(\mathrm{N}=431)$.

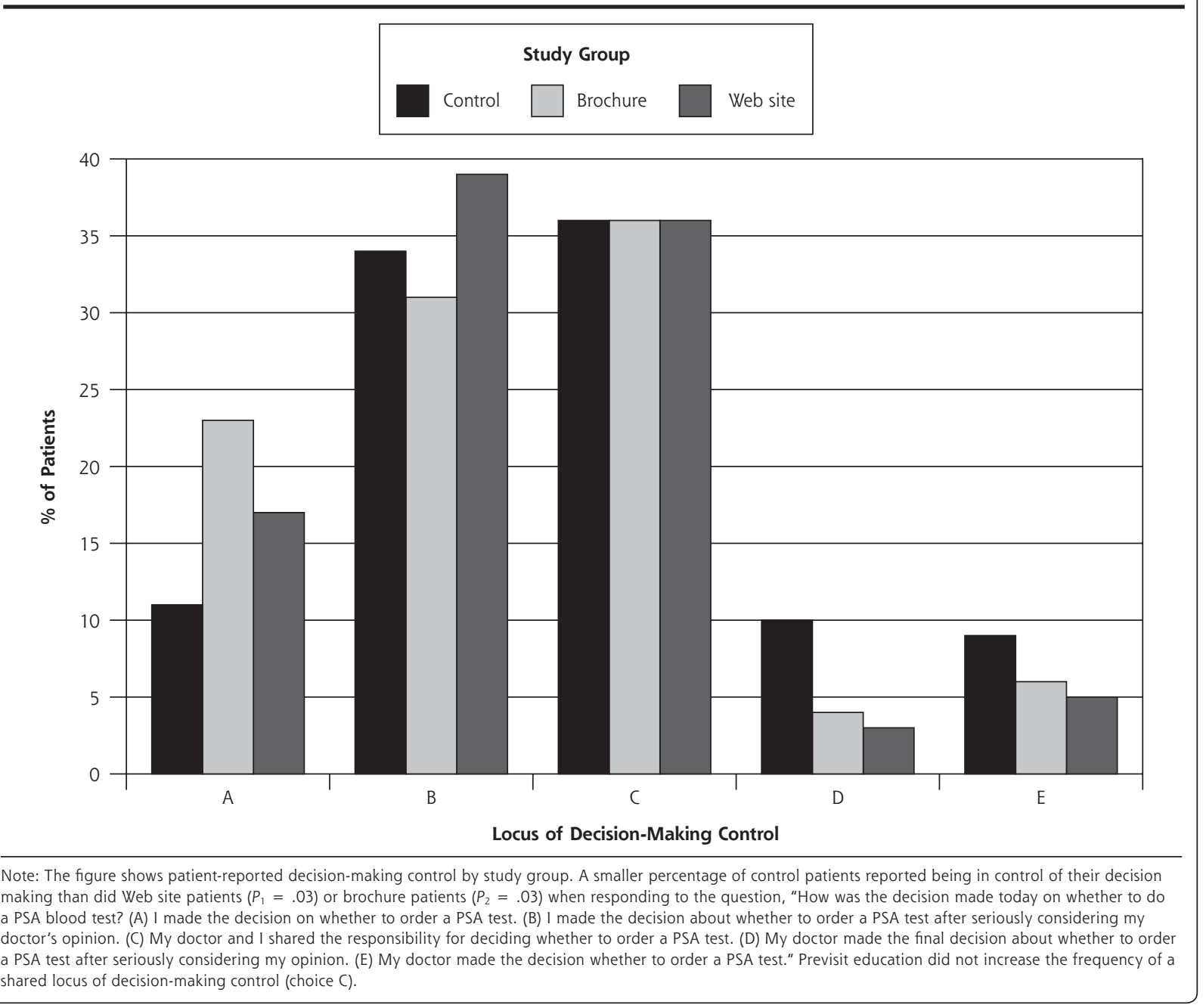


Figure 3. Patients' actual and desired locus of decision-making control $(\mathrm{N}=431)$.

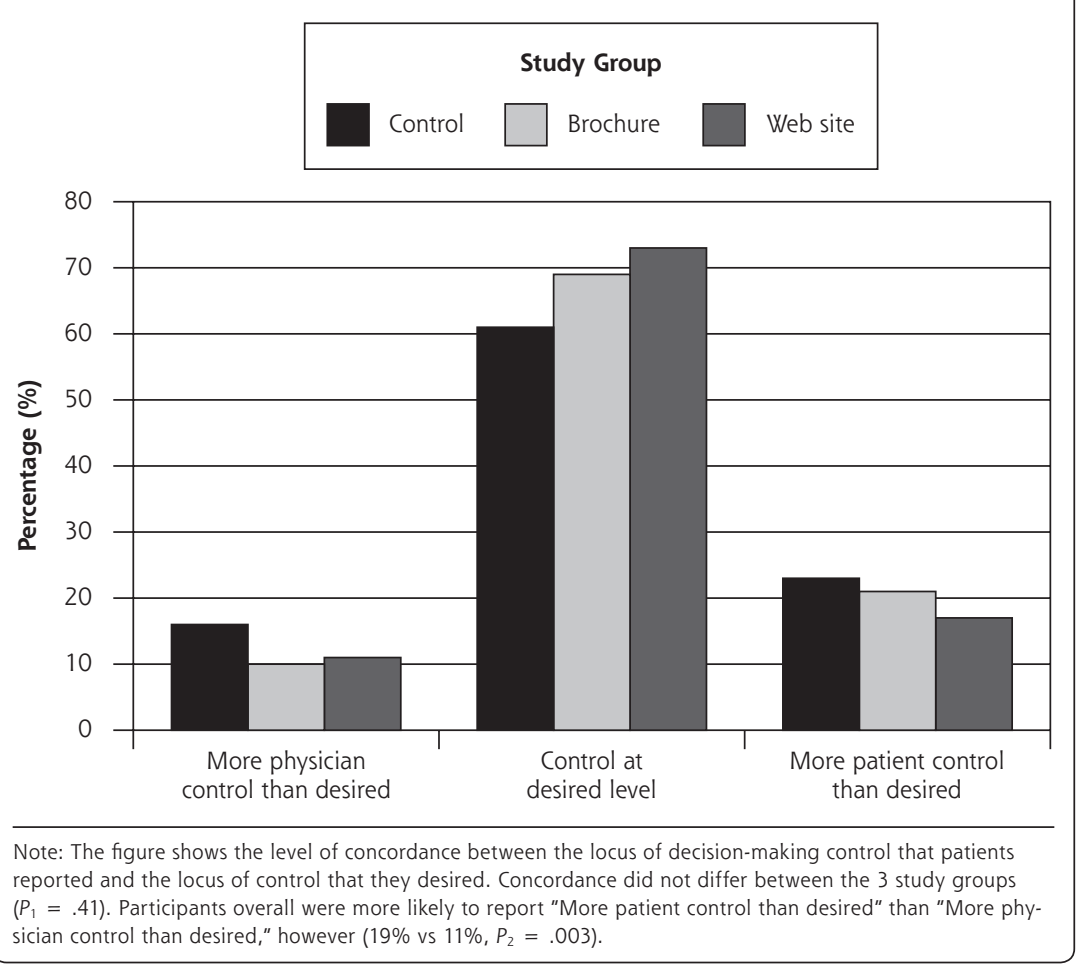

Table 2. Additional Characteristics of the Prostate Cancer Screening Decision-Making Process

\begin{tabular}{|c|c|c|c|}
\hline Characteristic & $\begin{array}{c}\text { Control } \\
\text { Group } \\
(n=75)\end{array}$ & $\begin{array}{c}\text { Brochure } \\
\text { Group } \\
(n=196)\end{array}$ & $\begin{array}{c}\text { Web Site } \\
\text { Group } \\
(n=226)\end{array}$ \\
\hline $\begin{array}{l}\text { Patients reported reviewing educational } \\
\text { material before visit, } \%\end{array}$ & 46 & 88 & 85 \\
\hline \multicolumn{4}{|l|}{ PSA test ordered } \\
\hline Patient report, \% & 85 & 83 & 86 \\
\hline Physician report, \% & $94^{*}$ & $85^{\dagger}$ & $86^{\ddagger}$ \\
\hline \multicolumn{4}{|l|}{$\begin{array}{l}\text { Relative frequency no time ( } 0 \text { minutes) was } \\
\text { spent discussing prostate cancer }\end{array}$} \\
\hline Patient report, \% & 2.7 & 1.0 & 3.1 \\
\hline Physician report, \% & 1.3 & 0.5 & 0.9 \\
\hline \multicolumn{4}{|l|}{ Minutes spent discussing prostate cancer } \\
\hline Patient report, mean (range) & $5.2(0-20)$ & $5.3(0-25)$ & $5.1(0-15)$ \\
\hline Physician report, mean (range) & $4.2(0-30)$ & $3.8(0-15)$ & $3.7(0-20)$ \\
\hline \multicolumn{4}{|l|}{ Number of prostate cancer topics discussed $\$$} \\
\hline Patient report, mean (range) & $4.3(0-10)$ & $4.9(0-10)$ & $5.0(0-10)$ \\
\hline Physician report, mean (range) & $5.2(0-10)$ & $5.1(0-10)$ & $5.0(0-10)$ \\
\hline $\begin{array}{l}\text { Percentage of knowledge questions patient } \\
\text { answered correctly }\end{array}$ & $54 \|$ & 69 & 69 \\
\hline Patient DCS score, mean (range) & $1.58(1-3.2)$ & $1.54(1-2.8)$ & $1.55(1-2.7)$ \\
\hline \multicolumn{4}{|c|}{$\begin{array}{l}\text { * Control group: patient-reported vs physician-reported frequency of PSA testing }(P=.06) \text {. } \\
\text { † Physician-reported frequency of PSA testing: brochure group vs control group }(P=.04) \text {. } \\
\text { † Physician-reported frequency of PSA testing: Web site group vs control group }(P=.06) \text {. } \\
\text { § Potential range: } 0 \text { to } 10 \text {. } \\
\text { || Control vs brochure group }(P<.001) \text {; control vs Web site group }(P<.001) \text {. }\end{array}$} \\
\hline
\end{tabular}

Even if shared decision making is the preferred approach, measuring its occurrence is difficult, as our findings highlight. One could measure a single surrogate outcome of the quality of the decision-making process, such as patient knowledge or decisional conflict. Although these outcomes are useful, improvements in these surrogates do not, by themselves, ensure that the decision-making process caused the improved outcome. We purposely measured multiple aspects of the decision-making process that are commonly studied when evaluating decision aids to seek a broader understanding of the entire decision-making process. Recently, several instruments have been developed that yield a numerical score on the quality of the process. ${ }^{35,36}$ Unfortunately, neither this score nor any other reference standard has emerged to define a decision as shared. ${ }^{30}$

If we adopt the 4 elements of the USPSTF definition of shared decision making (described earlier), we would conclude that our decision aid improved 2 elements-knowledge of the disease and of screening - but not the other 2 elements-consideration of patients' values and engagement in the decision at the desired level. Assessing whether these changes represent an improvement in shared decision making is problematic. If shared decision making is reduced to these 4 scales, at what threshold for each of these scales can we say that shared decision making occurred? What if some elements are done well and others are not? Does increased patient knowledge qualify as shared decision making? Is discordance between desired and actual decision-making control incompatible with shared decision making?

Our study has several important limitations. First, we 
measured outcomes by patient and physician questionnaires as opposed to direct observation or interview. Second, we studied a well-educated, computer-savvy patient population that may be more likely to use a Web-based decision aid. Internet use has become increasingly more commonplace across demographic groups, however. ${ }^{37}$ The rapid increase in the number of available Web-based educational aids attests to the need to study the Web as a medium for enhancing patient education. Third, in July 2003, the study practice lost a well-publicized malpractice case involving shared decision making and prostate cancer screening. ${ }^{9}$ A temporal analysis suggested that the ruling had no apparent impact on the locus of decision-making control or participant enrollment. ${ }^{38}$ Although there was a slight increase in the PSA testing rate from before to after the lawsuit (from $84 \%$ to $90 \%$ of encounters, $P$ $=.06$ ), trends were similar across the 3 study arms. ${ }^{38}$ In addition to being highly educated, our study population had a relatively high PSA testing rate in both decision aid arms and before the publicized lawsuit; however, similarly high testing rates have been seen in several studies evaluating prostate cancer screening decision aids in similar situations, ${ }^{14,15,22,39}$ and educated populations presenting for wellness services (as we have studied) are more likely to receive PSA testing. Fourth, $46 \%$ of control patients reported that they viewed educational material before the office visit. It is unlikely that they viewed our decision aid, as it is not available at an obvious URL on the Web. Viewing other publicly available educational material before their visit may have dampened the incremental effect of our decision aids. Finally, our study was underpowered to detect differences between the brochure and Web site groups. A significant difference between these groups is unlikely, given our current findings.

In conclusion, simple paper- and Web-based decision-making aids were equally effective at promoting patient activation in the decision-making process and educating patients. Whether the aids increased shared decision making is less clear. Further research to define and measure shared decision making is required before the utility of aids can be fully understood.

To read or post commentaries in response to this article, see it online at http://www.annfammed.org/cgi/content/full/5/2/112.

Key words: Prostatic neoplasms; decision making; patient education/ methods; guideline adherence/statistics $\&$ numerical data; prostatespecific antigen/blood; mass screening/methods; prevention/cancer; information management

Submitted December 13, 2005; submitted, revised, April 17, 2006; accepted May 27, 2006.

Funding support: This work was funded by the American Academy of Family Physicians Foundation under the Joint Grant Awards Program.
Acknowledgments: We would like to thank the faculty, residents, and patients of Fairfax Family Practice Center at the VCU School of Medicine/INOVA campus for participation in and assistance with this study, as well as Robert Volk, PhD, and Annette O'Connor, PhD. We would also like to thank Theodore Ganiats, MD, for sharing copies of a decision aid, developed for the American Academy of Family Physicians, to which we referred in developing our instrument.

\section{References}

1. Stamey TA, Caldwell M, McNeal JE, et al. The prostate specific antigen era in the United States is over for prostate cancer: what happened in the last 20 years? J Urol. 2004;172(4 Pt 1):1297-1301.

2. Thompson IM, Pauler DK, Goodman PJ, et al. Prevalence of prostate cancer among men with a prostate-specific antigen level $<$ or $=4.0$ ng per milliliter. $N$ Engl J Med. 2004;350(22):2239-2246.

3. Prostate-specific antigen (PSA) best practice policy. American Urological Association (AUA). Oncology (Williston Park). 2000;14(2):267272, 277-268, 280 passim.

4. Summaries for patients. Screening for prostate cancer: a recommendation from the U.S. Preventive Services Task Force. Ann Intern Med. 2002;137(11):148

5. Smith RA, Cokkinides V, von Eschenbach AC, et al. American Cancer Society guidelines for the early detection of cancer. CA Cancer J Clin. 2002;52(1):8-22.

6. Sheridan SL, Harris RP, Woolf SH. Shared decision making about screening and chemoprevention. A suggested approach from the U.S Preventive Services Task Force. Am J Prev Med. 2004;26(1):56-66.

7. Hurtado MP, Swift EK, Corrigan JM, eds. Envisioning the National Healthcare Quality Report. Washington DC: Institute of Medicine; 2000. Available at: http://www.nap.edu/books/030907343X/html/. Accessed: 25 January 2005.

8. Yarnall KS, Pollak KI, Ostbye T, Krause KM, Michener JL. Primary care: is there enough time for prevention? Am J Public Health. 2003;93(4):635-641.

9. Merenstein D. A piece of my mind. Winners and losers. JAMA. 2004;291(1):15-16.

10. Schwartz LM, Woloshin S, Fowler FJ Jr, Welch HG. Enthusiasm for cancer screening in the United States. JAMA. 2004;291(1):71-78.

11. Woolf $\mathrm{SH}$, Krist $\mathrm{A}$. The liability of giving patients a choice: shared decision making and prostate cancer. Am Fam Physician. 2005;71(10):1871-1872.

12. Davison BJ, Kirk P, Degner LF, Hassard TH. Information and patient participation in screening for prostate cancer. Patient Educ Couns. 1999;37(3):255-263.

13. Volk RJ, Cass AR, Spann SJ. A randomized controlled trial of shared decision making for prostate cancer screening. Arch Fam Med. 1999;8(4):333-340.

14. Frosch DL, Kaplan RM, Felitti V. The evaluation of two methods to facilitate shared decision making for men considering the prostatespecific antigen test. J Gen Intern Med. 2001;16(6):391-398.

15. Schapira MM, VanRuiswyk J. The effect of an illustrated pamphlet decision-aid on the use of prostate cancer screening tests. J Fam Pract. 2000;49(5):418-424.

16. Wolf AM, Nasser JF, Schorling JB. The impact of informed consent on patient interest in prostate-specific antigen screening. Arch Intern Med. 1996;156(12):1333-1336.

17. Wantland DJ, Portillo CJ, Holzemer WL, Slaughter R, McGhee EM The effectiveness of Web-based vs. non-Web-based interventions: a meta-analysis of behavioral change outcomes. J Med Internet Res. 2004;6(4):e40.

18. Baker $L$, Wagner TH, Singer S, Bundorf MK. Use of the Internet and e-mail for health care information: results from a national survey. JAMA. 2003;289(18):2400-2406. 
19. American Academy of Family Physicians. Should you get a PSA test? A patient-doctor decision. Available at: http://www.aafp.org/ online/etc/medialib/aafp_org/documents/clinical/patient_ed/prostatescreening_patient.Par.0001.File.tmp/prostate_patient_tool.pdf. Accessed: 25 January 2005.

20. Mayo Clinic. Prostate cancer screening: know your options. Available at: http://www. mayoclinic.com/invoke.cfm?objectid=E3657711F837-4DE5-A8BC93BC4D0EE475. Accessed: 25 January 2005.

21. Centers for Disease Control and Prevention. Prostate cancer screening: a decision guide. Available at: http://www.cdc.gov/cancer/prostate/publications/decisionguide/. Accessed: 25 January 2005.

22. Frosch DL, Kaplan RM, Felitti VJ. A randomized controlled trial comparing Internet and video to facilitate patient education for men considering the prostate specific antigen test. J Gen Intern Med. 2003;18(10):781-787.

23. Woolf SH, Krist AH, Johnson RE, Stenborg PS. Unwanted control: how patients in the primary care setting decide about screening for prostate cancer. Patient Educ Couns. 2005;56(1):116-124.

24. Krist A, McCormally T. What patients want from their doctor's website, poster abstract. Fam Med. 2001;33:552.

25. Department of Family Medicine, Virginia Commonwealth University. Should you get a PSA test? A patient-doctor decision. Available at: http://www.acorn.fap.vcu.edu/psa/. Accessed: 18 March 2005.

26. Degner LF, Sloan JA. Decision making during serious illness: what role do patients really want to play? J Clin Epidemiol. 1992;45(9):941-950.

27. Degner LF, Sloan JA, Venkatesh P. The Control Preferences Scale. Can J Nurs Res. 1997;29(3)21-43.

28. O’Dell KJ, Volk RJ, Cass AR, Spann SJ. Screening for prostate cancer with the prostate-specific antigen test: are patients making informed decisions? J Fam Pract. 1999;48(9):682-688
29. O'Connor A. Decisional Conflict Scale. 4th ed. Ottawa, Ontario: University of Ottawa; 1999.

30. Elwyn G, Edwards A, Mowle S, et al. Measuring the involvement of patients in shared decision-making: a systematic review of instruments. Patient Educ Couns. 2001;43(1):5-22.

31. SAS. Version 9.1.3. Copyright 2002-2003. Cary, NC: SAS Institute Inc

32. O'Connor AM, Legare F, Stacey D. Risk communication in practice: the contribution of decision aids. BMJ. 2003;327(7417):736-740.

33. O'Connor AM, Stacey D, Entwistle V, et al. Decision aids for people facing health treatment or screening decisions. Cochrane Database Syst Rev. 2003;(2):CD001431.

34. McNutt RA. Shared medical decision making: problems, process, progress. JAMA. 2004;292(20):2516-2518.

35. Elwyn G, Edwards $A$, Wensing $M$, et al. Shared decision making: developing the OPTION scale for measuring patient involvement. Qual Saf Health Care. 2003;12(2):93-99.

36. Edwards A, Elwyn G, Hood K, et al. The development of COMRADE - a patient-based outcome measure to evaluate the effectiveness of risk communication and treatment decision making in consultations. Patient Educ Couns. 2003;50(3):311-322.

37. Pew Internet and American Life Project. Internet usage over time. Available at: http://www.pewinternet.org. Accessed: 18 March 2005

38. Krist A, Woolf $S$, Johnson R. How physicians approach prostate cancer screening before and after losing a lawsuit. Ann Fam Med. 2007;5(2)120-125.

39. Flood AB, Wennberg JE, Nease RF, Jr., et al. The importance of patient preference in the decision to screen for prostate cancer. Prostate Patient Outcomes Research Team. J Gen Intern Med. 1996;11(6):342-349.

\section{CHANCE-OF-ADDRESS FORM FAMNILY MEDICINE}

Please complete this form and mail to the following address or fax to Annals Circulation at 913-906-6080:

Annals of Family Medicine, Circulation Department, 11400 Tomahawk Creek Pkwy, Leawood, KS 66211-2672

Check if member of sponsoring organization: $\square$ AAFP $\square$ ABFM $\square$ STFM $\square$ ADFM $\square$ AFMRD $\square$ NAPCRG

ID number from label on your journal cover

OLD Information (Please print.)

Name

Company (if applicable)

Address (Street plus Apt or Ste)

City

Country

Telephone

Fax

E-Mail
NEW Information (Please print.)

\section{Name}

Company (if applicable)

Address (Street plus Apt or Ste)

City State

\begin{tabular}{ll}
\hline Country & Postal Code (9-digit ZIP for US)
\end{tabular}

Telephone Fax

E-Mail 